\title{
Impact of Upper Tropical Cyclone on West Bank of Bohai Sea
}

\author{
Zhiming Yu Siyao Wang \\ The Tangshan City Meteorological Bureau \\ Tangshan 063000 China \\ qasqxjyzm@163.com

\begin{abstract}
Based on the data of FY-2E infrared cloud image, radar, micaps3.1, island observation station, large buoy, and numerical weather forecasting products, effects of tropical storm Damrey on Tangshan were analyzed, forecast and disaster cause of tropical storm Damrey were also analyzed. The results show that the mesoscale low pressure system, going into the west area of $38^{\circ} \mathrm{N}, 121^{\circ} \mathrm{E}$, will move toward north fast along the 586 line of the subtropical high. When more than $39^{\circ} \mathrm{N}$, the system will turn to northeast by the effect of westerlies, and move faster. Double effect of ultra low level southeast jet on the sea was obvious, not only is the power factor but also the water vapor factor. Strong precipitation and wind of Damrey appears at the point, which is the inflection point of the line 586 of the subtropical high on 500hpa upper weather map. Leting County flooded seriously because of the 5 consecutive rainstorms and the storm surge of Damrey.
\end{abstract}

Keywords-Damrey; Forecast; Disaster; Storm surge

摘要一利用 FY-2E 红外云图、雷达、micaps3.1、海岛站、 大浮标站及数值产品检验资料, 分析了进入渤海的热带风暴 “达维” 对河北省唐山市的影响，对 “达维” 的预报和造成灾 害的成因进行了研究。结果表明: 进入 $38^{\circ} \mathrm{N}, 121^{\circ} \mathrm{E}$ 以西的 中尺度低压系统, 将会沿副高 586 线边缘快速北上, 超过 $3^{\circ}$ $\mathbf{N}$ 时, 在西风带作用下移向转为东北, 移速加快。“达维” 进 入渤海后海区超低空东南急流 “双重效应” 明显, 既是动力因 子又是水汽短时输送因子, 产生的强降水位于 500 百帕高空图 “586 脊线” 拐点处; 前期连续出现的五次暴雨和 “达维” 产 生的风暴潮使乐亭县出现了严重的内港灾害。

关键词—“达维”，预报，灾害，风暴潮

\section{I. 引言}

台风的破坏力主要是由强风、暴雨和风暴潮三个因素 引起的, 给沿海各省市的工农业生产、交通运输和人民 生命财产安全造成严重威胁和极大损失, 一直被广大气 象工作者 ${ }^{[1 、 2]}$ 所关注。2012 年 8 月 3 日-8 月 4 日位于山 东半岛北部 “达维” 台风北移及副热带高压东退, 在渤 海西部海区-海岸带形成 3 维空间有利于强降水的形势场 和 NE-SW 向次天气尺度雨带, 并在秦皇岛海区中尺度 低层辐合风场、水汽因子耦合下，导致区域性大暴雨及 大风天气的发生。近年来, 许多学者对如何避免和减轻 的热带气旋的损失进行了研究与探讨 $[3$-4]开展过大规模 的热带气旋外场 ${ }^{[5]}$ 监测及数值模拟 ${ }^{[6-7]}$ 试验, 对热带气 旋的运动突变、结构、强度变化和热带气旋暴雨 ${ }^{[8.9]}$ 等方 面进行了一系列 ${ }^{[10]}$ 的研究, 一些科研成果在多次热带气 旋预报中得到了较好的应用。据统计，2005 年至 2017 年影响渤海及沿岸地区的热带气旋仅有 5 次, 分别为 2005 年的 “麦莎”、2011 年的 “梅花” 及 “米雷”、2014 年的 “麦德姆” 和 2017 年的 “海棠”。目前对于热带气

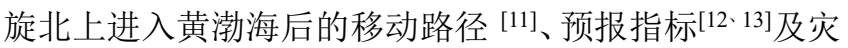
害成因 ${ }^{[14]}$ 仍处于探讨阶段, 相关的研究很少。2012 年进 入渤海的 “达维” 是 1949 年以后登陆我国长江以北地区 最强的热带气旋, 唐山市气象台对 “达维” 进行了系统 的分析, 做出了较准确的预报, 进行了较成功的服务。 但在前期连续出现 5 次暴雨的背景下, 受 “达维” 造成 的大风、强降水和农历十五天文大潮影响, 唐山东南部 沿海的乐亭县仍出现了严重的内涝灾害。

本文以 2012 年进入渤海海域的热带风暴 “达维” 为 例, 通过对 “达维” 的预报着眼点、难点的总结和乐亭 
县发生严重内涝灾害的成因分析, 以积累北上热带气旋 的暴雨和风暴潮预报方法, 为黄渤海及沿岸地区抵御热 带气旋灾害提供参考。

\section{II. “达维”概况及对唐山的影响}

\section{A. “达维” 概况}

1210 号热带气旋 “达维” 7 月 28 日 20 时生成, 7 月 31 日 8 时加强为强热带风暴, 8 月 1 日 8 时加强为台风, 下午进入黄海, 强度继续加强, 于 8 月 2 日 21 时 30 分 前后在江苏省响水县陈家港镇沿海登陆。之后, “达维” 于 8 月 3 日 1 时在江苏省连云港市减弱为强热带风暴, 9 时在山东沂源县减弱为热带风暴。 4 日凌晨 2 时进入渤 海, 之后强度继续减弱。上午 8 时, 热带风暴“达维”在 河北省东北部近海减弱为热带低压, 11 时停止编号。

\section{$B$. 唐山实况监测资料}

受 “达维” 影响, 3 日白天到 4 日上午, 唐山有 67 个乡镇雨量超过 100 毫米, 雨量从西北至东南向呈梯度 递增分布, 有 15 个乡镇雨量超过 200 毫米, 有 4 个乡镇 雨量超过 250 毫米, 过程最大降水量出现在乐亭县王滩 镇为 279 毫米。

\section{C. 灾情概况}

河北省唐山市的乐亭县降水量最大, 受灾最重, 8 月
2 日 7 时至 4 日 5 时乐亭全县普降大暴雨到特大暴雨, 乐亭县出现严重内涝, 据民政部门统计, “达维” 造成全 县 531 个村受灾, 倒塌房屋 6000 多间, 90\%的沿海养殖 户 “血本无归”。经济损失 42 亿元。

\section{III. 预报着眼点和难点}

\section{A. 预报着眼点}

1) “达维” 路径预报：8月 2 日 8-17 时, 副高脊线 位于 $35^{\circ} \mathrm{N}$ 附近, “达维”一直处在副高南缘稳定的偏 东气流中, 并沿引导气流向西偏北移动。对 “达维” 出 现了日本传真图、EC、T639 预报路径及中央台、省台预 报意见存在分歧情况。唐山市气象台参考 7 月 21 日后 5 次暴雨落区, 分析 500 百帕高空形势场副热带高压和 925 百帕风场对中尺度低压系统的影响 (图 1); 实时对比日 本传真图、EC、T639、中央台数值产品检验资料; 查阅 了 “麦莎”、“米雷” 及 “梅花” 的环流形势、云图特征 和移动路径。 2 日 17 时得出结论: 进入 $38^{\circ} \mathrm{N}, 121^{\circ} \mathrm{E}$ 以西的中尺度低压系统, 将会沿副高 586 线 (500 百帕 高空图 584 线和 588 线之间增划的等值线) 边缘快速北 上, 超过 $39^{\circ} \mathrm{N}$ 时, 在西风带作用下移向转为东北, 移 速加快。“达维” 符合以上特征, 将主要影响唐山东南部 沿海地区。
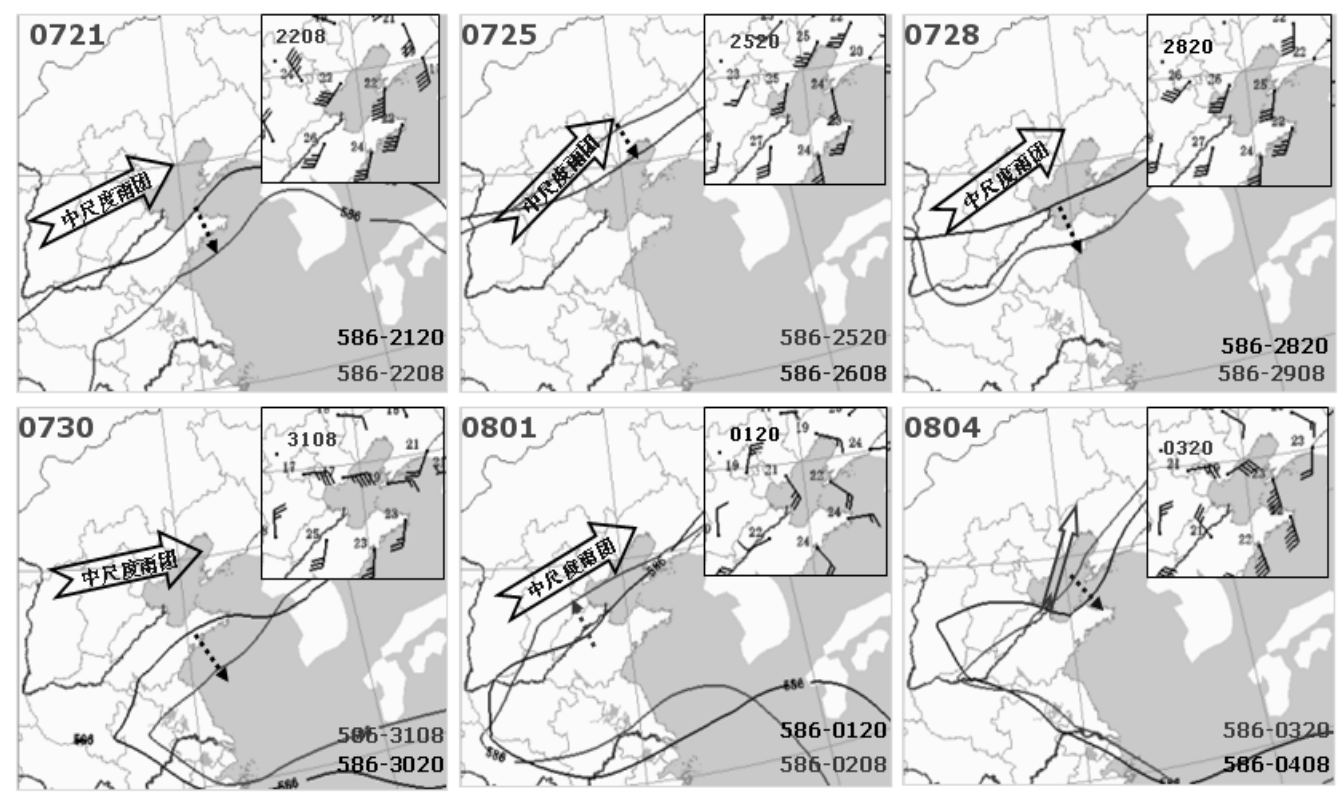

图 1 六次强降水过程 500 百帕 “586 线” 12 小时动态与 925 百帕风场叠加图

2) 动力和水汽分析: 8 月 2 日 20 时, 通过分析未来 12-24 小时副热带高压 586 线位置, 近地面、925 百帕水 平风场特征, 3 日 8 时 925 百帕 “达维” 东侧的东南风
急流与 “苏拉” 东北侧的东南风急流将叠加在一起, 1000-925 百帕存在明显低空东南风急流 (图 2)。海区超 低空东南急流动力抬升和水汽输送 “双重效应” 明显, 
既是动力因子又是水汽短时输送因子, 强的东南急流配 维” 提供了有利的动力和水汽条件。 合宽而深厚的水汽输送带及垂直向的水汽输送，为 “达

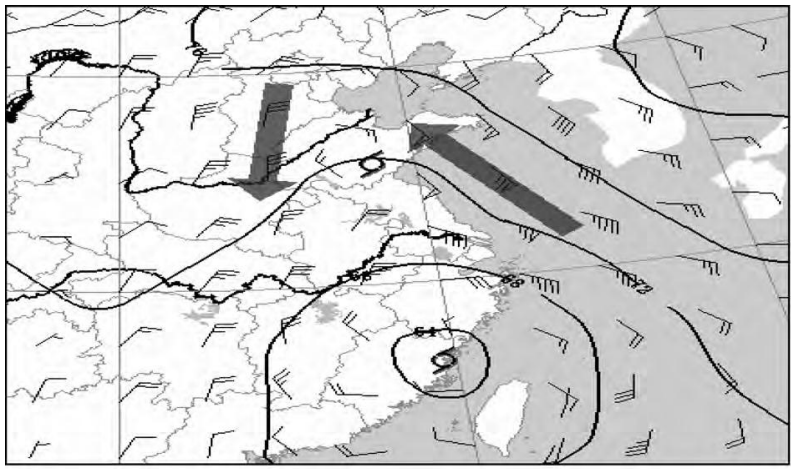

图 22012 年 8 月 3 日 08 时 925 百帕高度场和风场叠加图

调阅红外云图与实况雨量叠加、雷达拼图、受“达维” 影响山东各观测站降水实况资料发现，2 日 14-3 日 8 时 山东半岛 9 个县市出现暴雨, 青岛胶南区降水达 108 毫 米。随着 “达维” 减弱继续向西北方向移动, 强降水落 区出现在 “达维” 移动方向的右侧和中心附近。参考最 新中央台热带气旋路径预报、中央台 6 小时雨量落区预 报, 实时对比 FY-2E 红外云图资料, 3 日 17 时预报结论： 强降水区位于 500 百帕高空图 “586 脊线” 拐点处唐山 的东部和东南部地区。“达维” 降水过程在唐山分为两个 时段： 8 月 3 日 20 时之前受热带气旋云系间接影响，主 要为副热带高压外围降水, 20 时之后受进入渤海的 “达 维” 主体云系影响, 3 日 20 时后降水强度将增强, 过程 雨量可大于 200 毫米。

\section{B. 预报难点}

预报难点之一是 “达维” 在江苏省陈家港镇登陆后移
动路径不确定, “达维” 浴旋状云系在进入渤海后加强的 依据不充分, 导致唐山市气象台预报的 “达维” 路径比 实际偏西偏北，预报的暴雨落区和单站大暴雨中心均偏 西偏北。预报难点之二是“双热带气旋直接或间接效应” 对系统移速及强度变化不确定, 2 日 17 时 48 小时预报 把 “达维” 视为 “副高边缘中尺度浴旋类” 天气系统, 预报过程降水量为大-暴雨级别。事实上 3 日 08 时 “达 维” 受副高 588 线边缘带状云系 (SE 引导气流) “牵制” 并从菲律宾东部海区热带云团中补充能量 (图 3); 20 时 副高西伸和 1209 号热带气旋 “苏拉” 北部中尺度云团发 展构成的径向超天气尺度云带, 在西风带和副高急流引 导下, 超天气尺度云带加快 NE 向移速脱离 “苏拉” 双 热带气旋效应的影响, 转为“副高边缘中尺度云团暴雨类 型”, “达维” 比 “副高边缘中尺度浴旋类” 天气系统移 动速度慢 6-8 小时, 3 日 17 时预报过程降水量更改为暴 雨-大暴雨级别。
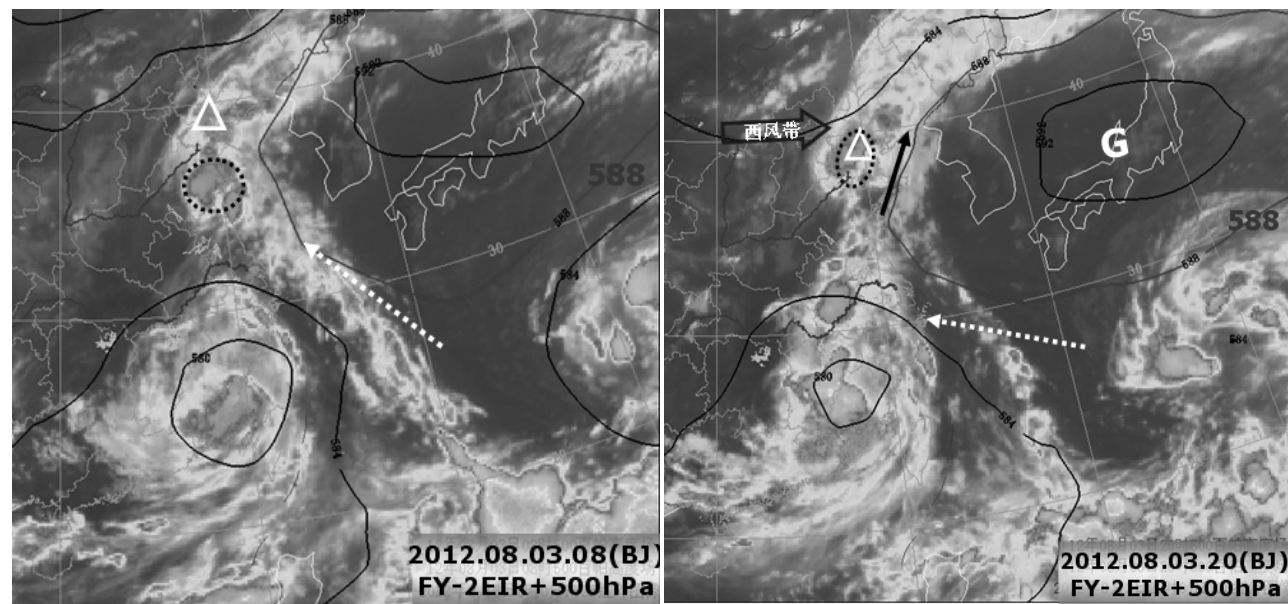

图 3 “达维” FY-2E 红外云图 12 小时对比及 500 百帕副高叠加分析图 


\section{IV 灾害成因分析}

\section{A.大风造成的增水影响}

唐山市乐亭县距天津塘沽的直线距离约 150 公里, 以 上天津塘沽闸下验潮站的增水资料可作为乐亭海域增水 的参考（表 1)。8 月 2 日 08 时一 3 日 08 时，期间 “达 维” 位于黄海中南部, 黄海中部受 “达维” 影响东南大 风明显, 黄海北部受偏东风控制（图 2), 导致黄海中部 大量水体不断向黄海北部涌入, 经渤海海峡进入渤海, 同时热带气旋 “苏拉” 位于东海南部，受 “苏拉” 东北
部东到东南大风影响, 使东海水体不断向黄海涌入; 两 者共同作用，使渤海水位不断升高，造成较大的增水，3 日 00 时增水值为 $116 \mathrm{~cm}, \circ 3$ 日下午到 4 日凌晨随着 “达 维” 在山东半岛继续北上, 渤海中西部东北风不断加大, 最大风力达 8-9 级阵风 10-11 级(图 4), 风增水明显; 前期涌入渤海的水体无法排出, 继续向渤海西部输送, 增水值进一步加大, 同时受 “苏拉” 的影响从东海南部 到黄海中部维持较大的东南风, 使东海至黄海中部的水 体仍向北涌入，3 日 23 时增水值达到 $137 \mathrm{~cm} \mathrm{，4} \mathrm{日} 01$ 时增水达最大值 $140 \mathrm{~cm}$ 。

表 1： 2012 年 8 月 2 日 08 时-4 日 08 时天津塘沽闸下验潮站增水实况（单位：CM）

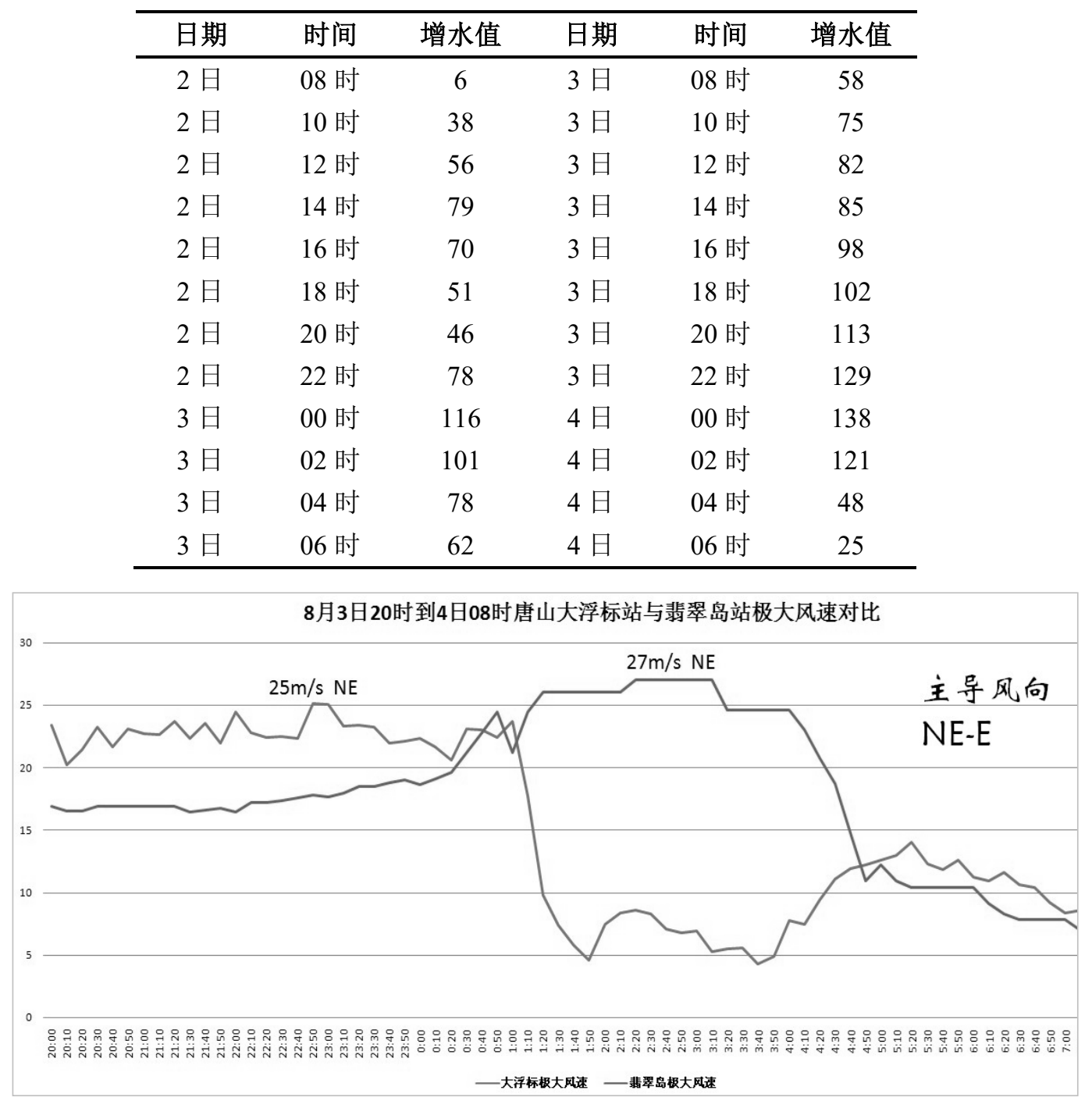

图 42012 年 8 月 3 日 20 时 4 日 08 时（北京时）唐山大浮标站与秦皇岛翡翠岛站风速(单位: $\mathrm{m} / \mathrm{s}$ )

\section{B. 连续六次强降水影响}

2012 年 7 月 21 日-8 月 4 日, 唐山连续出现 6 次强降 水天气过程, 平均降水量大于 400 毫米。3 日, 唐山上 游的大黑汀、潘家口等水库库容压力剧增, 水库加大泄
洪，使流经乐亭县的滦河和小青河水位迅速上涨。

\section{C. 天文大潮影响}

乐亭县地势低平，西北高、东南低，东南部沿海海拔 
高度不足 1 米, 8 月 3 日恰逢阴历六月十六天文大潮期,3 日 17 时天津塘沽闸下最高潮位达 $507 \mathrm{~cm}$, 此时增水值为 $106 \mathrm{~cm}$ (表 2), 高潮位和大风引起的渤海湾增水导致渤海
海平面上涨，使乐亭境内㴒河和小青河入海口水面低于 海平面，海水倒灌，河水长时间难以退却，河水漫过堤 坝。

表 2: 2012 年 8 月 2 日 08 时-4 日 08 时天津塘沽闸下验潮站潮位观测值（单位: CM）

\begin{tabular}{cccccc}
\hline 日期 & 时间 & 潮位值 & 日期 & 时间 & 潮位值 \\
\hline 2 日 & 08 时 & 145 & 3 日 & 08 时 & 225 \\
2 日 & 10 时 & 102 & 3 日 & 10 时 & 141 \\
2 日 & 12 时 & 188 & 3 日 & 12 时 & 185 \\
2 日 & 14 时 & 366 & 3 日 & 14 时 & 371 \\
2 日 & 16 时 & 451 & 3 日 & 16 时 & 499 \\
2 日 & 18 时 & 413 & 3 日 & 18 时 & 465 \\
2 日 & 20 时 & 311 & 3 日 & 20 时 & 412 \\
2 日 & 22 时 & 272 & 3 日 & 22 时 & 311 \\
3 日 & 00 时 & 364 & 4 日 & 00 时 & 338 \\
3 日 & 02 时 & 405 & 4 日 & 02 时 & 421 \\
3 日 & 04 时 & 451 & 4 日 & 04 时 & 407 \\
3 日 & 06 时 & 367 & 4 日 & 06 时 & 329 \\
\hline & & & & &
\end{tabular}

\section{V. 结论与讨论}

1) “达维” 移动到 $38^{\circ} \mathrm{N}, 121^{\circ} \mathrm{E}$ 附近, 将会沿副高 586 线边缘快速北上，超过 $39^{\circ} \mathrm{N}$ 时，在西风带作用下 移向转为东北, 移速加快。

2) “达维”进入渤海后海区超低空东南急流 “双重效 应” 明显, 既是动力因子又是水汽短时输送因子, 产生 的强降水区位于 500 百帕高空图 “588 脊线” 拐点处。 强降水过程分为两个时段： 8 月 3 日 20 时之前受热带气 旋云系间接影响, 主要为副热带高压外围降水, 20 时之 后受进入渤海的“达维”主体系统云系影响。

3)因风暴潮的增水效应导致的海平面升高，连续强 降水和上游水库放水导致河水上涨, 河水入海口低于海 平面使洪水长时间难以退却，海水倒灌，风雨潮三碰头 导致乐亭县出现了严重的内涝灾害。

\section{致谢}

本项目受环渤海区域科技协同创新基金项目 “黄渤海 雷暴大风监测及预警指标研究” (编号：QYXM201502) 资助。
参考文献

[1] 方宗义, 许健民, 赵凤生, “中国气象卫星和卫星气象研究的回顾 和发展, ”气象学报, vol.62, issue5, pp.550-560, 2004

[2] 陈联寿, “热带气旋研究和业务预报技术的发展, ”应用气象学报, vol.17, issue6, pp.672-681, 2006.

[3] Li Yuhong, Shi Lian, Wang Jiazhuo, "Pluvial Flooding Risk Analysis and the Solutions to Risk Mitigation for Dangyang City in China ," Journal of Risk Analysis and Crisis Response, vol.5, issue2, pp.107-119, 2015.

[4] Li Shuaijie, Xie Yingxia, Cheng Xiaotao, "Utilization of Flood Simulation Technique in Urban Flood Warning - A Case Study on Fuzhou,” Journal of Risk Analysis and Crisis Response, vol. 5, issue 2,pp.120-128, 2015.

[5] 毕宝贵, 林建, 徐晶, “气象卫星资料在天气预报分析业务中的应 用.”气象, vol..30, issue11, pp.19-23, 2004.

[6] 李燕, 黄振, “对"麦莎"路径及造成黄渤海域大风浪的数值模拟, ” 气象科技, vol.35, issue2, pp.175-179, 2007.

[7] 刘学刚, 李庆宝, 张金艳, “近年来引发青岛暴雨的台风特征分析, ” 气象, vol.37, issue9, pp.1091-1099, 2011.

[8] 刘健, 张文建, 朱元竞, “中尺度强暴雨云团云特征的多种卫星资 料综合分析,”应用气象学报, vol.18, issue2, pp.158-164, 2007.

[9] 何立富, 尹洁, 陈涛, “0509 号台风麦莎的结构与外围暴雨分布特 征, ”气象, vol.32, issue3, pp.93-100, 2006.

[10] 张玲, “2010 年西北太平洋和南海台风特点及其与冷空气相关的 预报难点分析，”天气预报技术总结专刊, vol.3, issue6, pp.16-24， 2011.

[11] 钱燕珍, 张寒, “台风森拉克路径特征与预报难点分析, ”气象, vol.30, issue9, pp.19-23, 2004.

[12] 黎惠金，覃昌柳，韦江红，“一次全区性较强降水空报的重大预报 失误过程分析,”气象, vol.31, issue1, pp.33-36, 2005.

[13] 王焕毅, 杨萌, 魏海宁, “台风达维路径变化及物理量诊断分析, ” 中国农学通报, vol30, issue8, pp.256-261, 2014.

[14] 王亚男, 王庆元, “1210 号台风大风和渤海湾天津沿岸风暴潮分 析[J], ” 海洋预报, vol.30, issue6, pp.7-12, 2013 . 